\title{
BackChat
}

\section{Years of medical experience versus parental instinct}

W hen I was 12 our dog had puppies. From my point of view it was a happy accident, and I watched the birth with great interest. She had four puppies; to the human eye they looked virtually identical. To my surprise she accepted and cared for three of the four puppies. Yet there was one she refused to have anywhere near her. My brave elder brother humanely destroyed the rejected pup, while mum explained the dog's instinct told her something was very wrong with the fourth pup. I wondered if humans were in possession of this instinct. I decided they probably were not; because friends of the family had a Down's syndrome child. Everyone accepted and loved this child even though all were aware he was "different $^{\prime \prime}$. Of course at $12 \mathrm{I}$ had no concept of the feelings of devastation that parents of a disabled child can feel when they first discover there is a problem.

I went on to work with children, many of whom had special needs. So the question could arise: Had my environment attuned me to problems in childhood? As it was often over a period of time that a child's difficulties became

Today marks the first of $A D C$ 's family pages. In every other issue we will be inviting a child, young person, or family member to tell us something about their experiences of their illness, disability, or the health care system. We start with a familiar plea and, in later issues, we will hear from a young man who doesn't want to wear a spinal brace, another who is working hard to come to terms with his Asperger's syndrome, and parents of sufferers from genetic rickets and neurofibromatosis type 1.

Poetry may join prose. We welcome contributions from your patients - who can submit electronically in the usual way or contact me on h.marcovitch@ btinternet.com.

Harvey Marcovitch

Syndication Editor, BMJ Publications apparent, I doubt this could explain the instant pang of inexplicable concern.

This is certainly what I felt at the birth of my first child nearly 17 years ago. His birth hadn't been entirely problem free-he was born with the cord round his neck. He was dark blue, quiet and limp; my first thought was "he's dead"-but as the midwife handed him to me I realised she wouldn't just hand me a dead baby and say nothing. After being taken back to the ward I put my concern down to exhaustion.

The following morning Andrew was brought back to me; now he looked like any other newborn baby. Yet for the first time I really understood what our dog had felt years ago. I looked at him and felt numb with fear, as the feeling that something was very wrong overwhelmed me. I didn't express my feelings to the staff, because he looked "normal" and I thought they would think I was mad and take him away.

My worries only increased when Andrew didn't appear to know how to suck. Staff explanations of "he is a boy and therefore lazy" were not helpful. At home things got worse; he would scream for hours and had an aversion to bright light and noise. Feeding was a frightening nightmare. Andrew never learnt to suck, and I secretly fed him on runny solids from a very early age. I couldn't tell the health visitor or GP what I was doing, because they really didn't appear to hear my concerns, and I believed they would criticise me for mishandling his care. I was made to feel any problems were entirely due to my anxiety of being a first time mum. I knew they were wrong, but I didn't have the words to push my point.

As Andrew left infancy, caring for him did get easier, as he began to sleep and eat. But the feeling of all was not well wouldn't go away; my husband didn't share these concerns at this stage. I felt utterly confused and would doubt my own sanity. When Andrew was 18 months old we had Jonathan; the difference between them was vast. Jonathan fed and slept to a point that fascinated me. For a brief period I felt the problems were behind us. However, as Jonathan developed he quickly overtook Andrew in speech, coordination, and understanding. Yet again I tried to express my concerns, particularly as extended family members had noticed Andrew was different. Unfortunately all I received was unsuccessful reassurance, mixed with our parenting being questioned.

When Andrew started school I soon realised he was very different to his peer group. Sadly over the years our expectations for him gradually fell. The education authority were just as resistant as the health professionals to admit Andrew had a problem. It was when dyspraxia was diagnosed privately that we finally saw a paediatrician and an educational statement was started. By this time Andrew was 9 years old, and over the next few years he was diagnosed with XYY syndrome, frontal lobe brain damage, autism, and possible hypoglycaemia. After a fight he was transferred to special school, where he became more secure.

The diagnoses were a vindication of my instinct, but the pain was added to by a lack of information and support each time. I was even shown an old medical text that described $X Y Y$ as a syndrome likely to produce a violent, antisocial male. I felt I would have rather been told his condition was terminal. To our great relief my own research proved this premise to be wrong.

Of course I understand doctors' time is limited and they can't be "the holder of all knowledge". I am sure there are parents who are over-anxious, who perceive problems where none exist. Yet I do suggest that a parent who expresses they "feel" all is not well, but can't articulate the problem, should at least have a follow up appointment to further check development. I also feel hospital managers might try to provide an information and counselling service for parents with concerns, even if their child is undiagnosed. Parents who feel supported are much more likely to cope.

S Travis 49 Clumber Avenue, Clayton, Newcastle-under-Lyme, Staffs ST5 3AY; susantravis@aol.com 